\title{
Influência da densidade de plantio e da cama de frango na produção da carobinha (Jacaranda decurrens Cham. ssp. symmetrifoliolata Farias \& Proença)
}

\author{
GOUVEA, A.B.; VIEIRA, M.C.*; HEREDIA Z., N.A.; PINTO, J.V.C. \\ Faculdade de Ciências Agrárias, Universidade Federal da Grande Dourados, UFGD, Caixa Postal 533, CEP \\ 79804-970, Dourados - Brasil. *vieiracm@terra.com.br
}

\begin{abstract}
RESUMO: Carobinha (Jacaranda decurrens Cham. ssp. symmetrifoliolata Farias \& Proença) é uma planta medicinal que ocorre no Cerrado de Mato Grosso do Sul. A espécie vem sendo amplamente utilizada pela medicina popular como depurativa do sangue e cicatrizante de feridas uterinas e dos ovários, resultando na sua exploração predatória. Por ser uma espécie identificada recentemente, os estudos sobre adaptação ex situ são ainda escassos. O objetivo deste trabalho foi avaliar o crescimento, o desenvolvimento, e a produção da carobinha cultivada ex situ em cinco espaçamentos entre plantas dentro das fileiras, em parcelas adubadas com e sem cama semidecomposta de frango de corte. O experimento foi desenvolvido no Horto de Plantas Medicinais (HPM) da Universidade Federal da Grande Dourados - UFGD, em DouradosMS, de abril de 2006 a outubro de 2007. Os espaçamentos entre plantas foram: 0,30; 0,35; 0,$40 ; 0,45$ e $0,50 \mathrm{~m}$, sendo a cama de frango aplicada na dose de $10 \mathrm{t} \mathrm{ha}^{-1}$ nas parcelas com este tratamento. $\mathrm{O}$ ensaio fatorial $5 \times 2$, foi conduzido no delineamento experimental de blocos casualizados, sendo a parcela constituída de $4,5 \mathrm{~m}^{2}$, com quatro repetições. As mudas foram obtidas a partir de sementes coletadas de uma população de 40 plantas nativas, distribuídas ao acaso, em área de cerca de $100 \mathrm{~m}^{2}$ com vegetação característica de Cerrado. Durante o cultivo avaliou-se a altura das plantas a cada 30 dias a partir de 150 até 480 dias após o transplante (DAT). As plantas foram colhidas aos 480 DAT, quando avaliou-se as massas fresca e seca da parte aérea, raízes, área foliar, e o comprimento e o diâmetro da maior raiz. A altura máxima $(1,58 \mathrm{~m})$ foi alcançada aos 471 DAT no espaçamento de $0,50 \mathrm{~m}$ entre plantas, tratadas com a cama de frango. Os dados de produtividade foram influenciados significativamente pelos espaçamentos, mas não pela adição da cama. O rendimento de massa seca das folhas por hectare não foi influenciado pelo espaçamento. A máxima área foliar foi obtida no espaçamento $0,50 \mathrm{~m}$. Os maiores valores de massa seca de caules por hectare ocorreram no espaçamento de $0,30 \mathrm{~m}$. Os maiores diâmetros de raiz, de xilopódio, e de caule, ocorreram no espaçamento $0,30 \mathrm{~m}$, sendo os máximos valores de comprimento de raiz e de xilopódio também observados neste espaçamento. Os maiores rendimentos de massa seca de raiz $\left(4,564 \mathrm{tha}^{-1}\right)$ e de xilopódio $\left(2,102 \mathrm{t} \mathrm{ha-1}^{-1}\right)$ foram obtidos no espaçamento $0,30 \mathrm{~m}$. Pelos resultados obtidos, concluiu-se que para se obter maiores produções de carobinha ela deve ser cultivada no espaçamento de 0,30 $\mathrm{m}$, independente da cama de frango.
\end{abstract}

Palavras-chave: Bignoniaceae, planta medicinal, planta nativa, resíduo orgânico

\begin{abstract}
Effects of plant density and the use of broiler litter on the Jacaranda decurrens Cham. ssp. symmetrifoliolata Farias \& Proença yield. Jacaranda decurrens Cham. ssp. symmetrifoliolata Farias \& Proenca, commonly known as carobinha, is a medicinal plant which occurs in the Cerrado of Mato Grosso do Sul. The species is widely used in folk medicine as a blood purifying and for healing wounds of uterine and ovarian cancers, which leads to its extensive and predatory exploitation. As it is a newly identified species, studies on its adaptation ex situ are still rare. Thus, the objective of this experiment was to evaluate the early development and yield of the species cultivated ex situ using five different plant spacing within the ranks and applying semicomposed broiler litter in the plots. The experiment took place at the Garden of Medicinal Plants from the Federal University of Grande Dourados ( UFGD), between April 2006 and October 2007. Plant spacings were: $0.30,0.35,0.40,0.45$ and $0.50 \mathrm{~m}$, with broiler litter applied at 10 ton ha-1 in plots. The $5 \times 2$ factorial trial was designed as randomized blocks, with
\end{abstract}

Recebido para publicação em 01/12/2009

Aceito para publicação em 28/02/2014 
$4.5 \mathrm{~m}^{2}$ plot area and four replications each. The seedlings were obtained from seeds collected in a natural germoplasm bank of 40 plants, randomly distributed in an area of about $100 \mathrm{~m}^{2}$ with typical Cerrado vegetation. During cultivation, the height of the plants was evaluated every 30 days from 150 to 480 days after transplanting (DAT). Plants were harvested at 480 DAT, when fresh and dry matter of shoots, roots, leaf area and length and diameter of the largest root were assessed. The maximum height $(1.58 \mathrm{~m})$ was reached at 471 DAT at $0.50 \mathrm{~m}$ spacing between plants when poultry litter was applied. The yield data were influenced significantly by the spacing, but not by the addition of the broiler litter. The yield per hectare of dry mass of leaves was not influenced by plant spacing, however maximum leaf area was also obtained at $0.50 \mathrm{~m}$ spacing. The highest values of dry mass of stems per hectare were obtained at $0.30 \mathrm{~m}$ between plants, as well as the largest diameters of root, xylopodium and stem and the maximum length of root and xylopodium was also observed under this plant spacing. Someway, the highest yields of dry mass of root (4.564 tha-1) and xylopodium (2.102 $\left.\mathrm{tha}^{-1}\right)$ occurred when used $0.30 \mathrm{~m}$ plant spacing. Based on these results, we concluded the species achieves higher yields when grown in $0.30 \mathrm{~m}$ plant spacing, independent of the addition of poultry litter.

Keywords: Bignoniaceae, medicinal plant, native plant, organic residue

\section{INTRODUÇÃO}

A carobinha (Jacaranda decurrens Cham. ssp. symmetrifoliolata Farias \& Proença), pertence a família Bignoniaceae e apresenta porte subarbustivo xilopodífero, ocorrendo no sudoeste do Mato Grosso do Sul. A espécie tem sofrido forte ação predatória pelo fato de suas raízes serem amplamente usadas na medicina popular no preparo de chás caseiros, como depurativa do sangue, e cicatrizante de feridas uterinas e dos ovários (Sangalli et al., 2002). Trata-se, portanto, de patrimônio genético pouco explorado e em risco de extinção considerando a escassez de estudos de adaptação ex situ dessa espécie frente à demanda crescente.

Segundo indicações populares, o chá da raiz da Jacaranda decurrens Cham. ssp. symmetrifoliolata Farias \& Proença é utilizado como depurativo do sangue e cicatrizante de feridas uterinas e dos ovários, para tratamento de infecções ginecológicas, giardíase, amebíase, e sífilis (Sangalli et al., 2002). Com relação às suas propriedades medicinais alguns estudos científicos já foram realizados, dentre eles: o de Medina et al. (2008), que, ao determinar a atividade antioxidante, avaliar os teores de flavonóides e de fenóis em folhas e raízes, verificaram que a subespécie é uma fonte rica em substâncias antioxidantes, tanto nas folhas como nas raízes, sendo que nessas últimas o potencial antioxidante foi maior. As raízes e folhas também são ricas em fenóis, enquanto as folhas contém flavonóides, demonstrando assim possibilidade das folhas serem usadas também como medicinais, e não apenas as raízes.

Objetivando avaliar os efeitos do chá da raiz de Jacaranda decurrens Cham. ssp. symmetrifoliolata na performance reprodutiva das ratas e os conceptos, Cunha-Laura et al. (2008) inferiram que o chá, no modelo experimental e na dose utilizada, parece ser desprovido de efeitos tóxicos sobre o organismo materno durante a organogênese (6 ao 15॰ DP), não afetando a evolução gestacional ou o desenvolvimento fetal durante toda a gestação $(1 \circ$ ao $20 \circ \mathrm{DP})$.

Em espécies medicinais, aromáticas e condimentares, Corrêa Júnior et al. (1994) e Mattos (1996) relatam que a adubação orgânica, o cultivo mínimo e as práticas de agricultura alternativa possibilitam o desenvolvimento de plantas mais resistentes às pragas e doenças $e$, consequentemente, menor utilização de agrotóxicos, que neste caso podem comprometer a composição química da planta, metabólitos primários e secundários, ou mesmo invalidar o uso medicinal. Os efeitos benéficos ao solo resultam, dentre outros, na melhoria das propriedades físicas, favorecendo a aeração e a capacidade de infiltração e armazenamento de água, permitindo maior penetração e distribuição do sistema radicular (Kiehl, 2008). Esse fato é essencial na produção da carobinha, visto que a raiz é a parte mais utilizada como medicinal.

Sangalli et al. (2008b) estudaram o crescimento e a produção da carobinha cultivada ex situ sob dois arranjos de plantas, sem ou com cama de frango semidecomposta e concluíram que o cultivo deve ser realizado em fileiras duplas. Em estudo sob $50 \%$ de sombreamento sob a influência de cinco diferentes substratos, Sangalli et al. (2008a) concluíram que o substrato Latossolo Vermelho distroférrico possibilitou às plantas crescerem e se desenvolverem mais.

Considerando a importância da raiz da carobinha, a ação indiscriminada para coleta de 
suas raízes, e a falta de estudos sobre essa espécie, o objetivo deste trabalho foi avaliar o crescimento, o desenvolvimento, e a produção da carobinha cultivada ex situ em cinco densidades de plantio, tratados com e sem cama de frango de corte semidecomposta.

\section{MATERIAL E MÉTODO}

O trabalho foi desenvolvido no Horto de Plantas Medicinais - HPM, da Universidade Federal da Grande Dourados - UFGD, em Dourados-MS, de janeiro de 2006 a outubro de 2007. O HPM está situado a $458 \mathrm{~m}$ de altitude, 22011'43.7" latitude Sul e S $054 \circ 56^{\prime} 08.5^{\prime \prime} \mathrm{W}$ de longitude. O clima regional é classificado, segundo o Sistema Internacional de Köppen (1948), como Cwa-Mesotérmico Úmido (MATO GROSSO DO SUL, 1990). A precipitação média anual é de $1500 \mathrm{~mm}$ e a temperatura média é de $22^{\circ} \mathrm{C}$. O solo, originalmente sob vegetação de Cerrado, segundo Embrapa (1999), é de topografia plana, sendo classificado como Latossolo Vermelho distroférrico, de textura muito argilosa, cujas características químicas são: $\mathrm{pH} 4,9 \mathrm{em} \mathrm{CaCl}_{2 ;} \mathrm{pH}$ 5,6 em água; $\mathrm{Al}^{+3} 0,6 \mathrm{mmol}_{\mathrm{c}} \mathrm{dm}^{-3} ; \mathrm{P} 24,0 \mathrm{mg} \mathrm{dm}^{-3} ; \mathrm{K}$

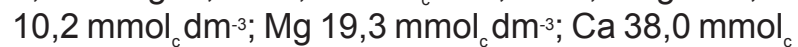
$\mathrm{dm}^{-3} ; 28,2 \mathrm{~g} \mathrm{~kg}^{-3}$ matéria orgânica; $65,0 \mathrm{mmol}_{\mathrm{c}} \mathrm{dm}^{-3}$ de acidez potencial; SB $67,5 \mathrm{mmol}_{\mathrm{c}} \mathrm{dm}^{-3} ; 132,5$ $\mathrm{mmol}_{\mathrm{c}} \mathrm{dm}^{-3}$ de CTC e $50 \%$ de saturação de bases. A cama de frango utilizada apresentou a seguinte composição: C orgânico 20,56\%; matéria orgânica $31,38 \% ; \mathrm{P}_{\text {total }} 28,50 \% ; \mathrm{K}_{\text {total }} 24,30 \% ; \mathrm{N}_{\text {total }} 1,87 \%$ e relação C/N 10,99.

Foi estudado o cultivo da carobinha em cinco espaçamentos entre plantas $(0,30 ; 0,35 ; 0,40$; 0,45 e $0,50 \mathrm{~m}$ ), correspondentes às densidades populacionais de 43.956; 37.620; 33.000; 29.304; e 26.400 plantas por hectare, respectivamente, e em solo sem e com cobertura com cama de frango de corte semidecomposta, na dose de $10 \mathrm{t} / \mathrm{ha}$. Os tratamentos foram arranjados em fatorial $5 \times 2$, no delineamento experimental de blocos casualizados, com quatro repetições. A altura das plantas foi avaliada durante o ciclo de cultivo, a cada 30 dias, considerados como parcelas subdivididas no tempo. A parcela foi de $4,5 \mathrm{~m}^{2}(1,5 \mathrm{~m}$ de largura $\times 3,0 \mathrm{~m}$ de comprimento) tendo área útil de $3,0 \mathrm{~m}^{2}(1,0 \mathrm{~m}$ de largura e 3,0 m de comprimento), contendo duas fileiras de plantas, espaçadas de $0,50 \mathrm{~m}$ entre as fileiras e entre as plantas.

A propagação foi feita por semeadura indireta, utilizando-se sementes coletadas de uma população de 20 plantas nativas, distribuídas ao acaso, em área de cerca de $100 \mathrm{~m}^{2}$ com vegetação característica de Cerrado, da Fazenda Lagoa Azul, localizada à margem direita da Rodovia BR $270, \mathrm{~km}$ 70 , Dourados a Itahum. As mudas foram produzidas em bandejas de poliestireno de 72 células, com substrato Bioplant ${ }^{\circledast}$, mantidas em ambiente protegido com sombrite ${ }^{\circledR} 50 \%$, com irrigações diárias. Após 70 dias da semeadura, quando as plântulas atingiram cerca de $10 \mathrm{~cm}$ de altura em média, foram transplantadas ao local definitivo. Imediatamente após o transplante foi feita a cobertura do solo com a cama de frango nas parcelas correspondentes.

Durante o ciclo de cultivo, foram feitas capinas com enxada para controle de plantas infestantes. As irrigações foram feitas por aspersão, com intuito de manter o solo com 70 a $75 \%$ da capacidade de campo. Não foi detectada ocorrência de pragas nem de doenças.

Durante o cultivo foi avaliada a altura das plantas a cada 30 dias, a partir dos 150 até 480 dias após o transplante-DAT, com auxílio de régua graduada, desde o nível do solo até a inflexão da folha mais alta. Aos 480 dias após o transplante - DAT foram colhidas duas plantas inteiras centrais da parcela, sendo uma de cada fileira, consideradas competitivas; depois, foram separadas as folhas, caules, raízes e xilopódios, quando se avaliaram suas massas frescas e secas, área foliar (determinada com o integrador foliar LICOR 3000), diâmetro do caule e da maior raiz, (medidos com paquímetro, a aproximadamente $1 \mathrm{~cm}$ acima e abaixo do coleto, respectivamente), e comprimento da maior raiz, (medido a partir do coleto até o ápice). Para obtenção da massa seca, todo o material foi seccionado e seco em estufa de circulação de ar forçada a $60^{\circ}+2^{\circ} \mathrm{C}$, até massa constante.

Os dados de altura de plantas foram submetidos à análise de variância em função dos tratamentos e de regressão em função dos dias após o transplante. As médias dos dados obtidos de produção foram submetidas à análise de variância e quando se verificou significância pelo teste $F$, foram ajustadas equações de regressão em função dos espaçamentos entre plantas, a $5 \%$ de probabilidade (Banzato e Kronka, 2006; Ribeiro Júnior, 2001).

\section{RESULTADO E DISCUSSÃO}

A altura das plantas apresentou crescimento quadrático e foi influenciada significativamente pela interação entre cama de frango e espaçamentos entre plantas. $O$ baixo desenvolvimento observado até os 150 dias pode ser atribuído às baixas temperaturas ocorridas no transplante realizado no outono e por um período de aclimatação no inverno. As maiores alturas das plantas durante todo o ciclo foram sob o espaçamento de 0,50 m entre plantas, sendo as máximas sem cama de frango $(1,47 \mathrm{~m})$ e $\operatorname{com}(1,51 \mathrm{~m})$ alcançadas aos 446 e 444 dias após o transplante, respectivamente (Figuras 1 e 2). Como as alturas foram semelhantes nos espaçamentos 
menores, deduz-se que a carobinha desenvolvese melhor crescendo a pleno sol. Já a ausência do efeito da cama de frango pode ser devido ao fato de que ela fora utilizada de forma semidecomposta e em cobertura, motivo pelo qual não tivera efeito direto na fertilidade do solo no período do ensaio. Desta forma, provavelmente os $28,2 \mathrm{~g} \mathrm{~kg}^{-1} \mathrm{de}$ matéria orgânica da própria composição do solo já tenham sido suficientes para suprir as necessidades da espécie que, por ser nativa de solo pobre, é pouco exigente em nutrientes.

A produtividade de massa seca das folhas por hectare não foi influenciada pelos espaçamentos entre plantas nem pelo uso da cama de frango (Figura 3 e Tabela 1). Este resultado deve-se, provavelmente, ao alto coeficiente de variação da característica avaliada, resultado da grande variabilidade genética da espécie, o que também foi constatado em populações nativas de Anemopaegma arvense (Vell.) Stellf. (catuaba) por Batistini (2006) e em Solanum lycocarpum (lobeira) por Santos et al. (2002).

Esses resultados também podem ser explicados por Larcher (2000) e Taiz e Zeiger (2004) quando citam que os sistemas vegetais têm mecanismos de auto-regulação, que se baseiam na capacidade de adaptação do organismo individual e nas populações ou no equilíbrio das relações de interferência, como competição por nutrientes, água e outros.

As áreas foliares das plantas de carobinha foram influenciadas significativamente pelos espaçamentos entre plantas, sendo a máxima obtida sob o espaçamento de 0,50 m (Figura 3). As oscilações das áreas foliares em função dos espaçamentos podem estar relacionadas mais à deciduidade da espécie do que à influência dos diferentes espaçamentos.

Sangalli et al. (2008a) citam que para a carobinha, o comportamento decíduo é um fator geneticamente determinado, fato que foi constatado em área nativa. Desta forma, a deciduidade é característica no ciclo de desenvolvimento da carobinha e ocorre paralelamente às estações outono-inverno, sendo neste período, a incidência de precipitações e as temperaturas geralmente inferiores às das demais estações. Já a fase de queda das folhas é seguida pela fase reprodutiva, ocorrendo o desenvolvimento acentuado de inflorescências, sendo que ao final da abertura dos botões florais inicia-se a fase da rebrota vegetativa, período coincidente com o início da primavera, quando as precipitações tendem a ser mais abundantes e as temperaturas mais elevadas. Nogueira Borges (2002) destaca a rebrota, como uma fase que aumenta a chance de sobrevivência de vegetais comercialmente importantes, como os utilizados na medicina popular e que habitam em áreas de intensa intervenção humana.

A ausência de influência significativa da cama de frango sobre as massas secas de folhas e área foliar (Tabela 1) pode estar relacionada ao fato da carobinha ser uma planta nativa, adaptada àquelas condições, sem que a quantidade da cama de frango adicionada ao solo como cobertura tenha sido suficiente para ocasionar mudanças nas características físicas, químicas e biológicas do solo que trariam resposta sobre a capacidade produtiva das plantas de carobinha. Este comportamento pode

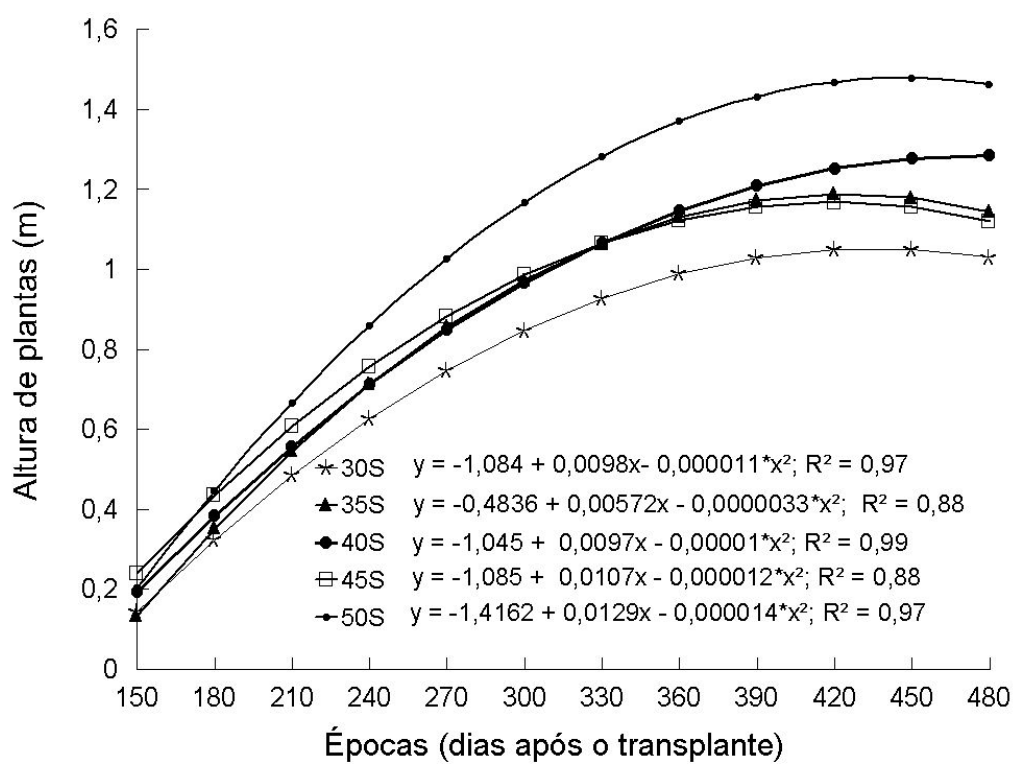

Figura 1. Altura de plantas de carobinha em função de dias após o transplante, cultivadas sob cinco espaçamentos entre plantas dentro das fileiras em solo sem cama de frango. Dourados, UFGD, 2006/2007. 


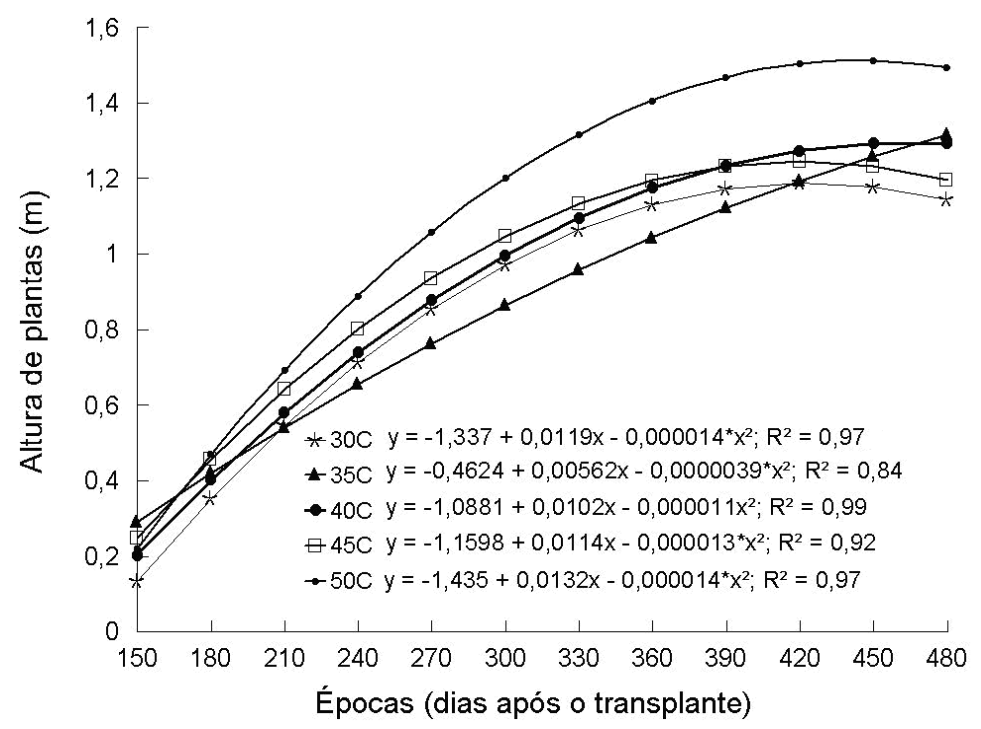

Figura 2. Altura das plantas da carobinha em função de dias após o transplante, cultivadas sob cinco espaçamentos entre plantas dentro das fileiras em solo com cama de frango. Dourados, UFGD, 2006/2007.

ser atribuído ao fato da carobinha ser endêmica de solo pobre em nutrientes e, portanto, pouco exigente quanto à nutrição e à estrutura física do solo.

Resultado semelhante foi obtido por Sangalli et al. (2008a) ao avaliarem o crescimento e desenvolvimento de Jacaranda decurrens Cham. ssp. symmetrifoliolata Farias \& Proença (Bignoniaceae) cultivada ex situ em condições de $50 \%$ de sombreamento sob a influência de cinco diferentes substratos, onde as produções de massas frescas e secas, da parte aérea e do sistema subterrâneo não foram influenciadas significativamente pelos substratos e sim pelas épocas de colheita.

As massas secas por hectare dos caules decresceram linearmente com o aumento dos espaçamentos entre plantas, sendo a máxima obtida no espaçamento $0,30 \mathrm{~m}$ (Figura 4). Por outro lado, não foram influenciadas significativamente pelo uso da cama de frango (Tabela 1).

Esses resultados indicam que os maiores valores foram devido, provavelmente, ao aumento do número de plantas ha-1 e não ao aumento da massa individual de cada planta. Fato que é reforçado por Heredia Zárate et al. (2000) que, estudando cinco clones de inhame (Dioscorea sp) sob 4.000; 8.000;

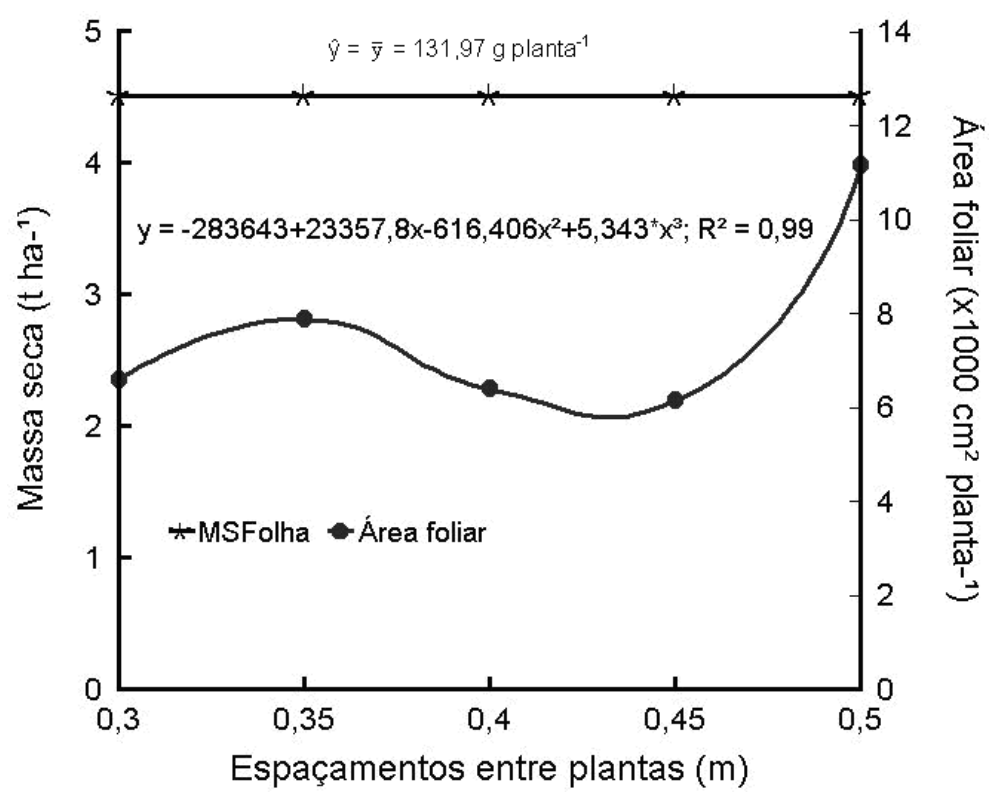

Figura 3. Massa seca (MSFolha) de folhas e área foliar de carobinha por hectare cultivada sob cinco espaçamentos entre plantas dentro das fileiras. Dourados, UFGD, 2006/2007. 
12.000 e 16.000 plantas ha-1 observaram que os aumentos obtidos sob as maiores densidades foram devido ao aumento do número de rizomas e/ou de tubérculos para cada clone, com base no número de plantas ha-1 e não devido ao aumento da massa individual desses rizomas e/ou tubérculos.

A influência de diferentes espaçamentos sobre a produção de biomassa varia com a espécie, a idade das plantas, e as características do local. Nos espaçamentos mais densos, a maior competição entre plantas resulta na estabilização do acúmulo de biomassa em menor idade, que aquela observada em espaçamentos mais amplos (Bernardo, 1995). Sendo que o maior espaçamento entre as culturas proporciona uma colheita com produtos maiores e o adensamento proporciona a redução do produto, porém uma maior produção (Primavesi, 1992).

As massas secas de raiz e xilopódios por hectare decresceram linearmente com o aumento dos espaçamentos entre plantas, sendo a máxima obtida sob o espaçamento de 0,30 m (Figura 5). Esses resultados indicam que os maiores valores foram devido, provavelmente, como exposto anteriormente ao aumento do número de plantas ha-1 e não ao aumento da massa individual de cada planta.

Os diâmetros do caule, da raiz e do xilopódio apresentaram respostas semelhantes, sendo as máximas obtidas no espaçamento de $0,30 \mathrm{~m}$, demonstrando com isso a interdependência entre eles, características para cada componente morfológico (Figura 6). Não foi observada diferença significativa sem ou com a adição de cama de frango (Tabela 2), devendo-se provavelmente ao fato da cama de frango adicionada ao solo como cobertura ter sido insuficiente para ocasionar mudanças nas características físicas, químicas e biológicas do solo, como já foi salientado para outras características.

Também, Sangalli et al. (2008a) observaram que o diâmetro dos caules e das raízes da carobinha não variaram significativamente em função dos

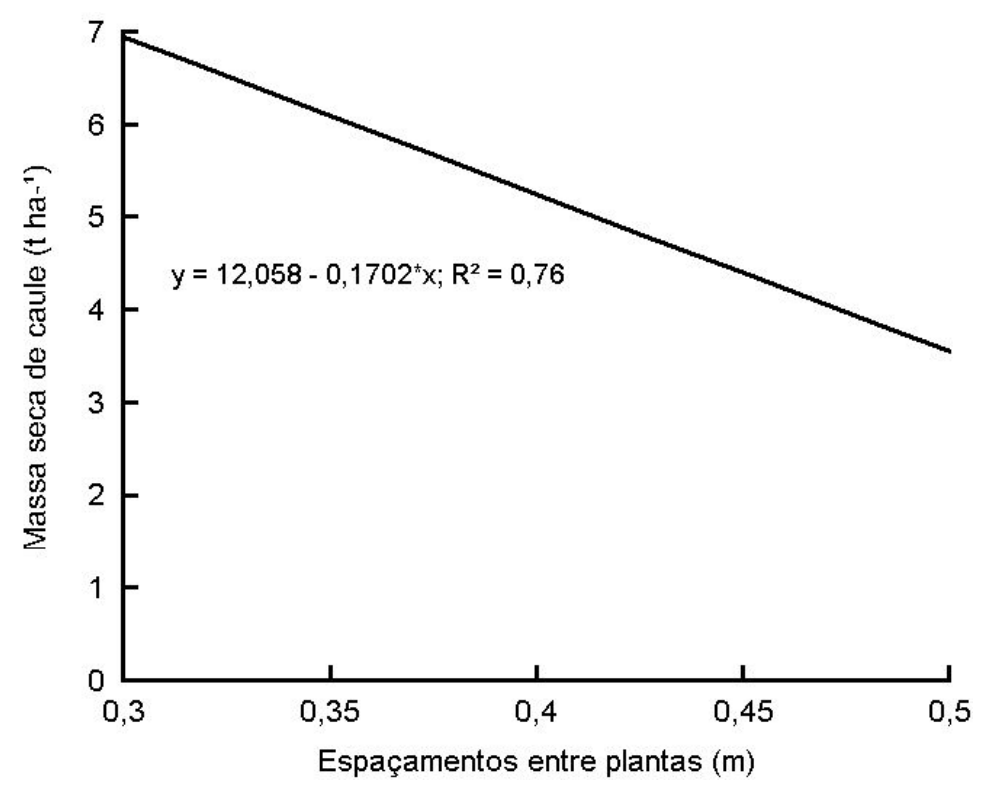

Figura 4. Massa seca de caule (MSC) de carobinha por hectare cultivada sob cinco espaçamentos entre plantas dentro das fileiras. Dourados - UFGD, 2006/2007.

Tabela1. Produção de massa seca das folhas, de caule, de raiz, de xilopódio e área foliar de plantas de carobinha cultivadas em solo sem e com cobertura com cama de frango de corte semidecomposta. Dourados, UFGD, 2006/2007.

\begin{tabular}{|c|c|c|c|c|c|}
\hline \multicolumn{5}{|c|}{ Massa Seca (t ha-1) } & \multirow{2}{*}{ Área foliar $\left(\mathrm{cm}^{2}\right.$ planta-1) } \\
\hline Cama de frango & Folhas & Caule & Raiz & Xilopódio & \\
\hline Sem & $4,24 \mathrm{a}$ & $5,10 a$ & $3,79 a$ & 1,68 a & $8186,165 a$ \\
\hline Com & $4,79 \mathrm{a}$ & $5,40 \mathrm{a}$ & $3,63 a$ & $1,74 \mathrm{a}$ & 7078,299 a \\
\hline C.V (\%) & 44,34 & 62,00 & 34,78 & 49,76 & 56,91 \\
\hline
\end{tabular}

Médias seguidas pela mesma letra, nas colunas, não diferem entre si pelo teste $F$, a $5 \%$ de probabilidade.

Rev. Bras. PI. Med., Campinas, v.16, n.3, p.481-489, 2014. 


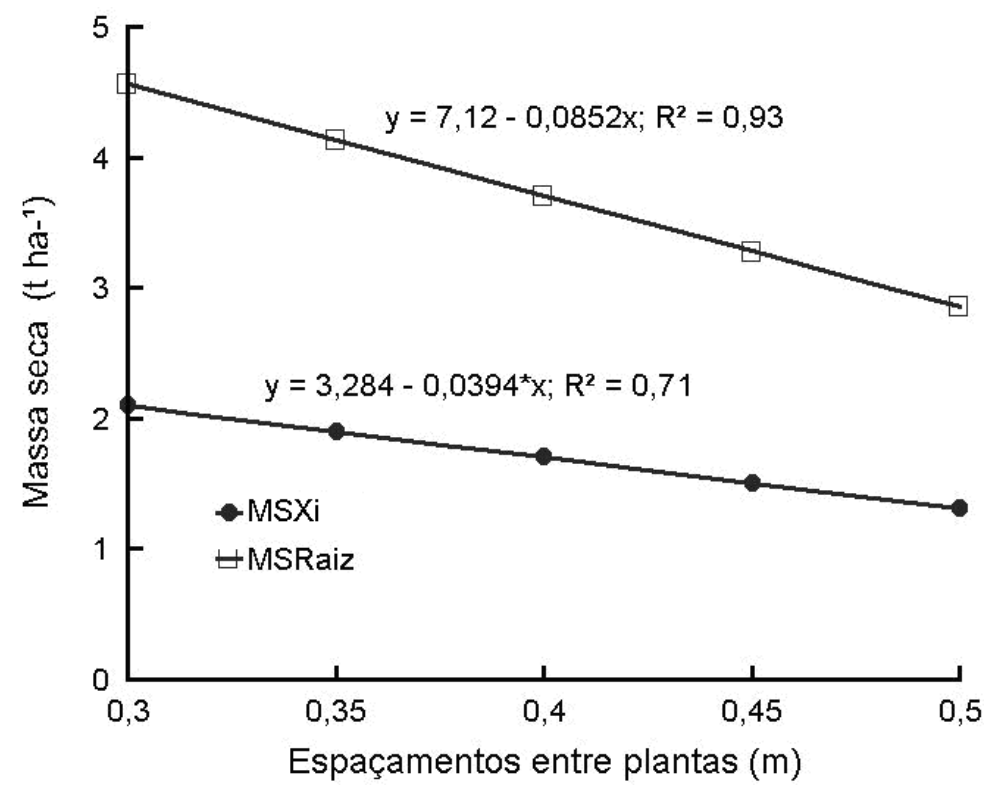

Figura 5. Massa seca de xilopódio (MSXI) e raiz (MSRaiz) de carobinha por hectare cultivada sob cinco espaçamentos entre plantas dentro das fileiras. Dourados - UFGD, 2006/2007.

substratos estudados, atribuindo isso ao fato da planta ser decídua e renovar anualmente suas folhas, investindo energia ao longo de sua vida para o desenvolvimento de estruturas como caule e sistema subterrâneo.

O menor comprimento das raízes obtido sob espaçamento de $0,50 \mathrm{~m}$ e maior no de $0,30 \mathrm{~m}$ (Figura 7), pode ser atribuído ao fato da planta ter investido mais na parte aérea, uma vez que a altura de plantas (Figuras 1 e 2) e a área foliar no mesmo espaçamento de $0,50 \mathrm{~m}$ apresentaram maiores valores, enquanto que no espaçamento de $0,30 \mathrm{~m}$ apresentaram os menores valores (Figura 3 ), tendo sido o acúmulo de fotoassimilados direcionado à parte aérea. Também pode ser devido ao fato das raízes da carobinha desenvolverem-se verticalmente no solo, sendo o maior adensamento das plantas fator não limitante de seu crescimento. Além disso, Larcher (2000) destaca que as características do solo influenciam o formato e a propagação da raiz,

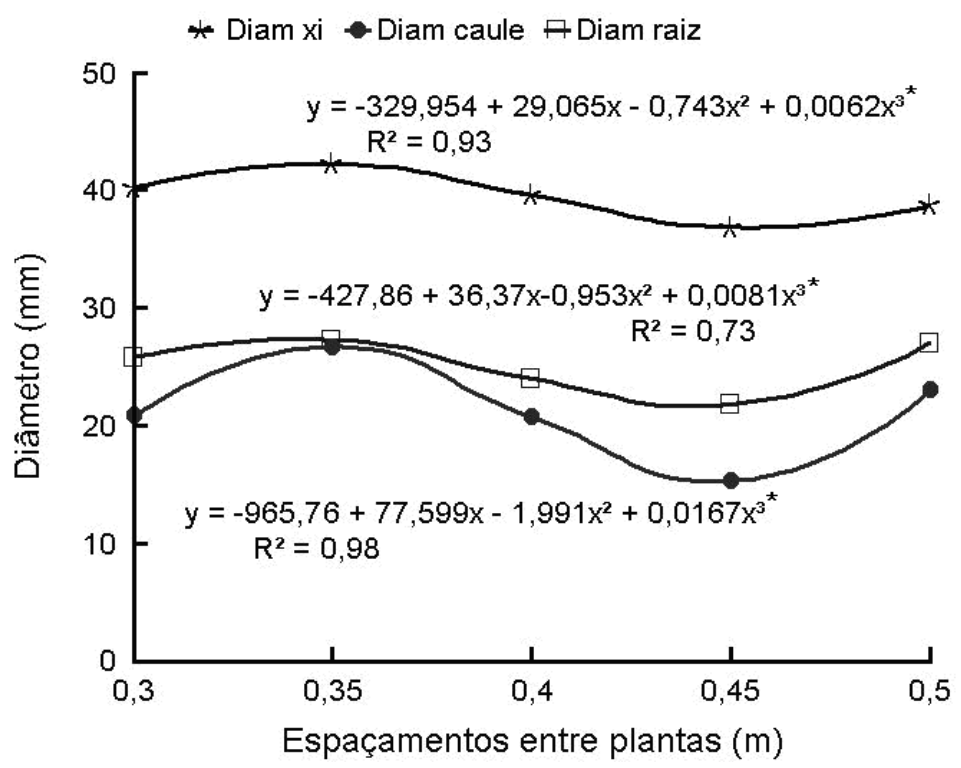

Figura 6. Diâmetro da raiz (Diam raiz), do xilopódio (Diam xi) e do caule (Diam caule) de carobinha em função do espaçamento entre plantas dentro das fileiras. Dourados, UFGD, 2006/2007. 
Tabela 2. Diâmetro (Diam) e comprimento (Comp) da raiz e do xilopódio de plantas da carobinha cultivadas sem e com cama de frango. Dourados, UFGD, 2006/2007

\begin{tabular}{lllllll}
\hline \multirow{3}{*}{ Cama de frango } & Raiz & \multicolumn{3}{c}{ Caule } & \multicolumn{3}{c}{ Xilopódio } \\
\cline { 2 - 7 } & $\begin{array}{l}\text { Diam } \\
(\mathbf{m m})\end{array}$ & $\begin{array}{l}\text { Comp } \\
(\mathbf{m})\end{array}$ & $\begin{array}{l}\text { Diam } \\
(\mathbf{m m})\end{array}$ & $\begin{array}{c}\text { Comp } \\
(\mathbf{m})\end{array}$ & $\begin{array}{c}\text { Diam } \\
(\mathbf{m m})\end{array}$ & $\begin{array}{c}\text { Comp } \\
(\mathbf{m})\end{array}$ \\
\hline Sem & $24,70 \mathrm{a}$ & $0,45 \mathrm{a}$ & $19.6470 \mathrm{a}$ & $2.3339 \mathrm{a}$ & $0,08 \mathrm{a}$ & $39,47 \mathrm{a}$ \\
Com & $25,80 \mathrm{a}$ & $0,44 \mathrm{a}$ & $22.4753 \mathrm{a}$ & $0.8037 \mathrm{a}$ & $0,09 \mathrm{a}$ & $39,71 \mathrm{a}$ \\
\hline C.V. $\%$ & 18,54 & 20,58 & 46,87 & 46,95 & 34,01 & 23,54 \\
\hline
\end{tabular}

Médias seguidas pela mesma letra, nas colunas, não diferem entre si pelo teste $F$, a $5 \%$ de probabilidade.

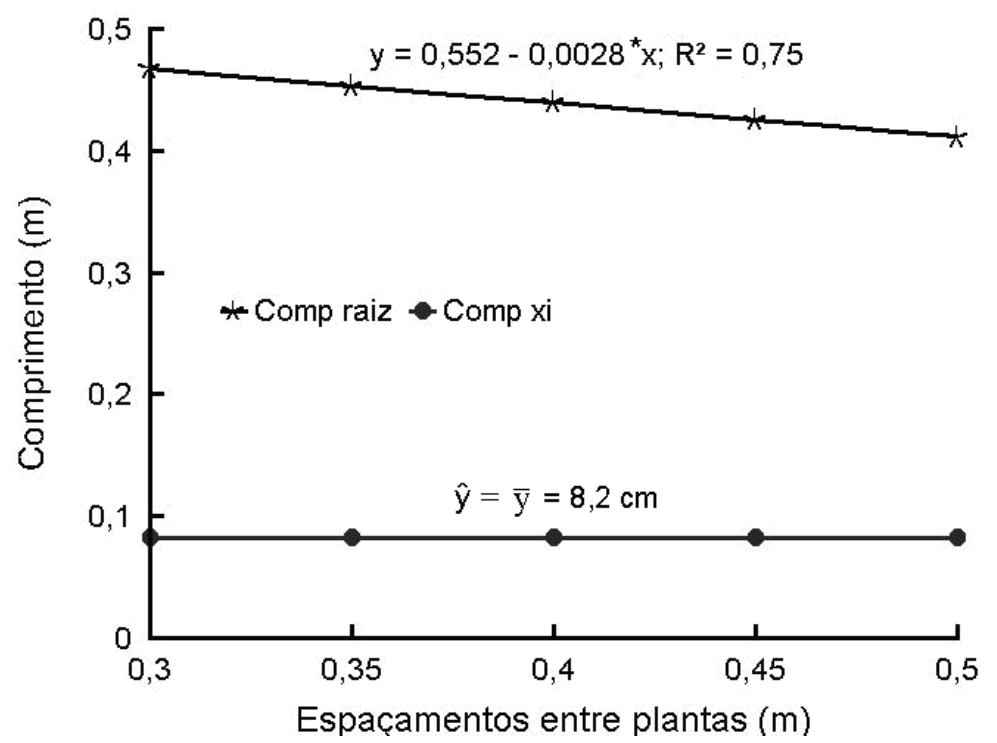

Figura 7. Comprimento da raiz (Comp raiz) e do xilopódio (Comp xi) da carobinha em função do espaçamento entre plantas dentro das fileiras. Dourados, UFGD, 2006/2007.

tendo o sistema radicular seu desenvolvimento dependente dos valores de $\mathrm{pH}$, conteúdo nutricional do solo, balanço hídrico, aeração, profundidade, dentre outras. Segundo Taiz \& Zeiger (2004), a relação raiz/parte aérea parece ser governada pelo balanço funcional entre a absorção de água pelas raízes e a fotossíntese pela parte aérea, sendo que a parte aérea continuará crescendo até que a absorção de água pelas raízes torne-se limitante, inversamente, as raízes crescerão até que a sua demanda por fotoassimilados da parte aérea igualese ao suprimento.

\section{CONCLUSÃO}

Um dos pontos críticos do cultivo da carobinha é o desenvolvimento lento, demorando 70 dias desde o semeio até o transplante e no mínimo um ano de ciclo para a primeira colheita das plantas.

Para condições semelhantes às da presente pesquisa, e para se obter maiores produtividades, as plantas de carobinha devem ser cultivadas com espaçamento de $0,30 \mathrm{~m}$ entre plantas, na fileira, independente do uso de cama de frango.

\section{AGRADECIMENTO}

À Fundação de Apoio ao Desenvolvimento do Ensino, Ciência e Tecnologia de Mato Grosso do Sul - Fundect, pelo apoio financeiro e ao Conselho Nacional de Desenvolvimento Científico e Tecnológico - CNPq, pelas bolsas concedidas.

\section{REFERÊNCIA}

AGUIAR, L.M.S.; MACHADO, R.B.; MARINHO FILHO, J.A. Diversidade biológica do cerrado. In: AGUIAR, L.M.S.; CAMARGO, A.J.A. (Ed.) Cerrado: ecologia e caracterização. Planaltina: Embrapa Cerrados, 2004. p.17-40.

BATISTINI, A.P. Diversidade morfológica, genética e química de populações naturais de Anemopaegma arvense (Vell.) Stellf. 2006. 83p. Tese (Doutorado Área de Concentração em Genética e Melhoramento de Plantas) - Faculdade de Ciências Agrárias e Veterinárias, Universidade Estadual Paulista, Jaboticabal.

BANZATO, D.A.; KRONKA, S.N. Experimentação 
agrícola. Jaboticabal: FUNEP, 1995. 247p.

BRASIL. Biodiversidade brasileira: avaliação e identificação de áreas prioritárias para conservação, utilização sustentável e repartição de benefícios da biodiversidade brasileira. Brasília: MMA/SBF, 2002. 404p.

CIPRIANI, F.A. Aspectos quimiotaxonômicos da família Bignoniaceae. 2006. 73p. Dissertação (Mestrado - Área de Concentração em Botânica) - Universidade Federal do Rio de Janeiro, Rio de Janeiro.

CORRÊA JÚNIOR, C.; MING, L.C.; SCHEFFER, M.C. Cultivo de plantas medicinais, condimentares e aromáticas. 2.ed. Jaboticabal: FUNEP, 1994. 162p.

CUNHA-LAURA, A.L. et al. Avaliação da ingestão do chá de carobinha durante a gestação de ratas Wistar. In: JORNADA ACADÊMICA DE MEDICINA DA UNIDERP, 5., 2008, Campo Grande. Resumos... Campo Grande: Ophiucus, 2008. p.38-42.

EMBRAPA. Empresa Brasileira de Pesquisa Agropecuária. Sistema brasileiro de classificação de solos. Rio de Janeiro: Embrapa CNPS, 1999. 412p.

FARIAS, R.; PROENÇA, C. Jacaranda decurrens subs. symmetrifoliolata FARIAS \& PROENÇA (Bignoniaceae), novo táxon para o bioma cerrado. BRADEA - Boletim do Herbarium Bradeanum, v.11, n.2, p.5-9, 2003.

FERREIRA, W.R.; RANAL, M.A.; FILGUEIRA, F.F.R. Fertilizantes e espaçamento entre plantas na produtividade da couve-da-Malásia. Horticultura Brasileira, v.20, n.4, p.635-40, 2002.

KIEHL E.J. Adubação orgânica - 500 perguntas e respostas. 2.ed. Piracicaba: Degaspari, 2008. 227p.

LARCHER, W. Ecofisiologia vegetal. São Carlos: RIMA. 2000. 531p.

MATO GROSSO DO SUL. Secretaria do Planejamento e Coordenação Geral. Atlas Multireferencial. Campo Grande: SEPLAN-MS, 1990. 28p.

MATTOS, J.K.A. Plantas medicinais: aspectos agronômicos. 1.ed. Brasília: Gutemberg, 1996. 51p.

MEDINA, A.F. et al. Determinação da atividade antioxidante e dos teores de flavonóides e fenóis em folhas e raízes de Jacaranda decurrens Cham. ssp. symmetrifoliolata Farias \& Proença cultivada ex situ. In: SIMPÓSIO BRASILEIRO DE PLANTAS MEDICINAIS, 10., CONGRESSO INTERNACIONALDE ETNOFARMACOLOGIA, 5., 2008, São Paulo. Annals and Program... São Paulo: SBPM, 2008. p.452.

NOGUEIRABORGES, H.B. Estudos sobre demografia de Heteropterys aphrodisiaca O. Mach. (Malpighiaceae): sobrevivência e reprodução no cerrado. Cuiabá: DCR/ UFMT, 2002. 29p. (Relatório Técnico DCR/CNPQ).

ORTOLANI, F. A. Morfo-anatomia, citogenética e palinologia em espécies de ipês (Bignoniaceae). 2007. 106p. Tese (Doutorado - Área de Concentração em Genética e melhoramento de plantas) - Faculdades de Ciências Agrárias e Veterinárias, Universidade Estadual Paulista, Jaboticabal.

PRIMAVESI, A.M. Agricultura sustentável. São Paulo: Nobel, 1992. 142p.

RIBEIRO JÚNIOR, J.I. Análises estatísticas no SAEG. Viçosa: UFV, 2001. 301p.

RODRIGUES, V.E.G.; CARVALHO, D.A. Levantamento etnobotânico de plantas medicinais no domínio dos cerrados na região do Alto Rio Grande - Minas Gerais. Revista Brasileira de Plantas Medicinais, v.9, n.2, p.17-35, 2007.

SANGALLI, A.; VIEIRA, M.C.; HEREDIA ZARATE, N.A. Levantamento e caracterização de plantas medicinais nativas com propriedades medicinais em fragmentos florestais e de cerrado, em Dourados-MS, numa visão etnobotânica. Acta Horticulturae, n.569, p.173-84, 2002.

SANGALLI, A. et al. Crescimento de Jacaranda decurrens Cham. ssp. symmetrifoliolata Farias \& Proença (Bignoniaceae) cultivada ex situ em condições de $50 \%$ de sombreamento. In: SIMPÓSIO BRASILEIRO DE PLANTAS MEDICINAIS, 20, INTERNATIONAL CONGRESS OF ETHNOFARMACOLOGY, 10., 2008a. São Paulo. Annals and Program... São Paulo: SBPM, 2008a. v.1. p.60. CD ROM.

SANGALLI, A.; VIEIRA, M.C.; HEREDIA ZÁRATE, N. A. Crescimento e produção de carobinha (Jacaranda decurrens symmetrifoliolata Faria \& Proença) cultivada sob dois arranjos de plantas, com ou sem cobertura de cama de frango no solo. Revista Brasileira de Agroecologia, v.3, p.134-37, 2008b.

SANTOS, M.O. et al. Variabilidade genética entre populações de lobeira (Solanum lycocarpum St. Hil.). Floresta e Ambiente, v.9, n.1, p.158-164, 2002.

TAIZ, L.; ZEIGER, E. Fisiologia vegetal. 3.ed. Porto Alegre: Artmed, 2004. 720p. 